\title{
A Persuasão Sensível no Texto Sincrético: uma Leitura Sociossemiótica
}

\author{
Sensitive persuasion in syncretic text: \\ a reading sociossemiótica
}

\section{Lyssandra Maria Costa Torres \\ Ricardo Lopes Leite \\ Universidade Federal do Ceará - UFC - Fortaleza - Brasil}

\begin{abstract}
Resumo: A Semiótica Discursiva, de origem francesa, estuda a argumentação como um conjunto de estratégias discursivas utilizadas na persuasão. Conforme essa vertente teórica, a eficácia da argumentação depende de acordos entre sistemas de valores, de um contrato enunciativo fundado em uma crença compartilhada entre enunciador e enunciatário. Assim, a argumentação diz respeito aos mecanismos mobilizados pelo enunciador para fazer o enunciatário crer no discurso enunciado para, consequentemente, conseguir sua adesão a um determinado fazer. Para se analisar as estratégias de persuasão/argumentação nos textos sincréticos, é preciso considerar uma enunciação global que articula as diferentes linguagens para produzir efeitos de sentido fundados não somente na dimensão inteligível do discurso, mas também na sua dimensão sensível. Com base nos regimes de sentido propostos por Eric Landowski (2014), este artigo analisa um anúncio publicitário de uma revista de cosmético para mostrar como diferentes regimes de sentido, dentre eles, a programação, a manipulação e o ajustamento, determinam diferentes estratégias de persuasão sensível no texto sincrético. Ao final, quer-se demonstrar que a eficácia da persuasão sensível reside na escolha de estratégias que levem o enunciatário não somente a aderir a um modo de pensar, mas também a um modo de sentir.
\end{abstract}

Palavras-chave: Persuasão. Argumentação. Sensível. Semiótica. Sincretismo.

Abstract: Discursive Semiotics, of French origin, studies the argument as a set of discursive strategies used in persuasion. According to this theoretical approach, the efficiency of the argument depends on agreements between value systems, a declarative contract based on a shared belief between enunciator and enunciatee. Thus, the argument refers to the mechanisms deployed by the enunciator to the enunciatee believe enunciated speech to consequently achieve their adherence to a particular make. To analyze the strategies of persuasion / argument in the syncretic texts, we need to consider a global enunciation that articulates the different languages to produce grounded sense of effects not only in the intelligible dimension of discourse, but also in its sensitive dimension. Based on regimes of sense, proposed by Eric Landowski (2014), this article looks at an advertisement of a cosmetic magazine to show how different regimes of sense, including, programming, handling and adjustment, determine different strategies sensitive persuasion in syncretic text. At the end, you want to demonstrate that the effectiveness of sensitive persuasion lies in choosing strategies that take the enunciatee not only to adhere to a way of thinking, but also a way of feeling.

Keywords: Persuasion. Argumentacion. Sensitive. Semiotics. Syncretism. 


\section{Introdução}

A argumentação é um tema multifacetado que remonta à retórica aristotélica e ecoa, hodiernamente, em diferentes perspectivas teóricas dos estudos da linguagem ${ }^{1}$. Por esse motivo, a formulação de uma definição global de argumentação será sempre redutora e arriscada, haja vista a quantidade de disciplinas interessadas pelo tema e o feixe de problemas e interrogações que ele suscita.

A Semiótica Discursiva, de origem francesa, acompanhando o movimento dos estudos atuais, amplia as concepções silogística (lógico-dedutiva) e retórica (apresentação e refutação de teses) de argumentação para estudar seu funcionamento discursivo, na medida em que todo discurso possui uma dimensão argumentativa, por conta de sua natureza dialógica. Sai-se, portanto, do domínio dos raciocínios necessários, utilizados para a demonstração de verdades lógicas, para o domínio dos argumentos preferíveis, que são aqueles baseados em crenças, visões de mundo $\mathrm{e}$ sentimentos, utilizados para convencer e/ou para comover.

Como a enunciação é o ato fundador do discurso e enunciar já é tomar posição em relação a um determinado ponto de vista, a eficácia da argumentação depende de acordos entre sistemas de valores, de um contrato enunciativo fundado em uma crença compartilhada entre enunciador e enunciatário. Assim, na perspectiva da Semiótica, a argumentação diz respeito aos mecanismos mobilizados pelo enunciador para fazer o enunciatário crer no discurso enunciado e consequentemente conseguir sua adesão a um determinado fazer. Por essa razão, as estratégias argumentativas podem ser vistas como organizações discursivas utilizadas na persuasão (BARROS, 2001; FIORIN, 2015).

Do ponto de vista semiótico, a dimensão argumentativa dos discursos não se restringe aos

\footnotetext{
${ }^{1}$ Como exemplos da variedade de abordagens, temos, além, é claro, da Retórica, de Aristóteles, as propostas de Perelman e Olbrechts- Tyteca (1999), Oswald Ducrot (1988), Ruth Amossy (2000) e José Luiz Fiorin (2015). Esses últimos podem ser apontados como abordagens mais discursivas da argumentação.
}

textos verbais, mas se manifesta igualmente nos textos sincréticos, aqueles que articulam mais de uma linguagem em seu plano da expressão. Para se analisar as estratégias de persuasão/argumentação nos textos sincréticos, é preciso considerar uma enunciação global que articula as diferentes linguagens para produzir efeitos de sentido fundados não somente na dimensão inteligível do discurso, mas também na sua dimensão sensível. Essa maneira de pensar a persuasão como um fenômeno tanto de natureza inteligível quanto sensível encontra respaldo na Sociossemiótica, proposta por Eric Landowski (2014). Nela, o autor propõe alguns regimes de sentido que determinam a construção da significação nos mais diversos textos, vistos como práticas sociocomunicativas. A escolha de um dos regimes de sentido envolve diferentes modos de interação entre enunciador e enunciatário e de estratégias que não dependem apenas da competência cognitiva, racional, para fazer o outro (dever, querer, poder) fazer, mas também de uma competência estésica para fazê-lo sentir.

Este artigo analisa um texto sincrético anúncio publicitário de um catálogo da marca Natura - para mostrar quais regimes de sentido estão envolvidos nele e como esses regimes orientam o fazer persuasivo do enunciador e 0 fazer interpretativo do enunciatário, ao criarem simultaneamente o simulacro da presença da dimensão inteligível e sensível do discurso nesse tipo de texto.

\section{Persuasão e argumentação em Semiótica Discursiva}

A Semiótica Discursiva é, em linhas gerais, uma teoria que estuda os mecanismos de produção da significação nos textos, sejam eles verbais ou não verbais. Trata-se de uma vertente teórica que procura descrever e explicar "o que o texto diz e como ele faz para dizer o que diz" (BARROS, 2005). Os estudiosos da teoria semiótica não se interessam pelo sentido propriamente dito, mas pelo "parecer do sentido", apreensível pela sua manifestação nos mais diversos 
discursos por meio de estruturas de linguagem, pois, somente assim, o sentido pode ser comunicado e compartilhado.

Para analisar os mecanismos de produção da significação nos textos e discursos, a Semiótica Discursiva utiliza um simulacro metodológico, chamado por Greimas de Percurso Gerativo do Sentido (PGS). Trata-se de um modelo que serve de grade metodológica para a análise do plano do conteúdo dos textos, com base em três níveis de abstração: o fundamental, o narrativo e o discursivo.

No nível fundamental, o mais simples do percurso, a significação é representada em um quadrado semiótico por meio de uma oposição semântica mínima, ou seja, baseia-se na relação entre dois primitivos semióticos, a versus $b$, como, por exemplo, vida versus morte, continuidade versus descontinuidade etc; categorias semânticas apresentadas de forma oposta no texto e que podem apresentar um valor eufórico (positivo) ou disfórico (negativo).

O nível narrativo, por sua vez, trata das relações de conjunção ou disjunção entre sujeitos e entre sujeitos e objetos, gerando transformações de estado. A Semiótica propõe fases para o esquema narrativo canônico, a saber, a manipulação (querer, dever), a competência (poder, saber), a performance (o próprio fazer) e a sanção (julgamento). Trata-se de um modelo de previsibilidade que dá conta da noção da narratividade, a começar pela manipulação argumentativa, que se realiza no discurso, mediante a ação de um enunciador que pretende conquistar a adesão de um enunciatário.

Os quatro tipos mais comuns de manipulação delimitados na teoria semiótica são a tentação (oferecimento de recompensa, de um objeto de valor eufórico para o manipulado), a intimidação (obrigação do fazer por meio de ameaças), a sedução (manifestação de juízo positivo sobre a competência do manipulado) e a provocação (juízo negativo sobre a competência do manipulado). É nesse âmbito que a persuasão é tratada - na relação com a manipulação - já que a narrativa constitui a própria comunicação entre os homens e pode estar sempre a serviço da persuasão por meio da articulação de um fazer persuasivo do destinador e de um fazer interpretativo do destinatário. Diante disso, percebe-se que, à luz da teoria semiótica discursiva, a persuasão pode ser vista como um fazer persuasivo ligado à instância da enunciação - fazer o outro fazer - e que a argumentação pode se caracterizar como uma parte da persuasão, já que é estratégica, afinal é por meio de estratégias argumentativas que a persuasão se faz, como deixa claro um exemplo do verbete Persuadir do Dicionário Houaiss eletrônico "Ex.: os argumentos não persuadiram", que revela a "dependência" entre metodologia argumentativa e persuasão. Percebe-se, com isso, que pode se realizar um estudo da argumentação como um programa de manipulação.

Dada a similaridade entre os conceitos de argumentação e persuasão, a fronteira entre eles é difícil de ser estabelecida. Os semioticistas Lopes e Beividas (2007), por exemplo, afirmam que o limite entre os dois conceitos pode ser estabelecido da seguinte forma: a argumentação seria um dos modos de operação da persuasão, enquanto esta seria uma dimensão maior que abarcaria a argumentação como subdimensão. Valendo-se do modelo greimasiano, Barros (1988, p. 98), por sua vez, assim relaciona persuasão e argumentação:

a Semiótica, ao pretender, no percurso gerativo, fazer a abstração da manifestação, interessa-se antes por estabelecer os recursos e os mecanismos gerais de argumentação, por meio dos quais 0 enunciador persuade 0 enunciatário (BARROS, 1988,p. 98)

Compreende-se que é por meio de mecanismos argumentativos que a persuasão ocorre, visto que há necessidade de o fazer persuasivo do enunciador/destinador estar em conjunção com o fazer interpretativo do enunciatário/destinatário para que haja adesão. É preciso, por conseguinte, que o destinatário/ enunciatário creia na "verdade" do discurso do destinador/ enunciador, de modo a validar a relação intersubjetiva. Enquanto a persuasão consiste em "fazer o outro fazer", a argumentação pode ser compreendida como um "como fazer o outro fazer". Logo, argumentação se trata de uma prática 
discursiva, um procedimento discursivo, que se estabelece, mas não somente, por meio de mecanismos e estratégias enunciativas, cuja finalidade é o estabelecimento de contato - maior ou menor - entre os participantes da enunciação. Como defende Teixeira (2006), "a argumentação se desenvolve como uma práxis enunciativa constituída (...) de um programa de manipulação que usa recursos de persuasão".

Apesar de a persuasão atravessar o nível narrativo, seus efeitos são mais bem captados pela análise do nível discursivo, quando as estruturas narrativas são enriquecidas discursivamente. Pelo enriquecimento da narrativa, é nesse nível do discurso, então, que se cria uma impressão de realidade. Como o texto é analisado como o resultado da enunciação, é nesse nível que se analisa as projeções da instância da enunciação no enunciado, bem como as relações entre enunciador e enunciatário, que podem ocorrer por meio dos mecanismos de debreagem e embreagem. Aquele pode ser enunciativo, quando ocorre a projeção do eu-aqui-agora, isto é, quando causa um efeito de proximidade actorial, espacial e temporal em relação ao enunciatário; e enuncivo, quando há projeção do ele-alhures-então, ou seja, quando os actantes, os espaços e os tempos da enunciação são omitidos, causando um efeito de distanciamento actorial, espacial e temporal. Ocorre embreagem quando a enunciação deseja criar determinados efeitos de sentido, como objetividade e subjetividade, através da "mescla" das categorias de debreagem, gerando, assim, uma suspensão cognitiva. Esses procedimentos podem representar mecanismos persuasivos pelos efeitos que geram: de objetividade e de subjetividade, ou seja, de distanciamento e aproximação em relação ao enunciatário, respectivamente.

Consoante Teixeira (2006), para tratar a argumentação como programa de manipulação, é necessário narrativizar o percurso do sujeito que enuncia, o que revela um forte limiar entre os níveis narrativo e discursivo. Além disso, é importante, para dar conta dos mecanismos argumentativos, considerar, ao lado das projeções de pessoa, tempo e espaço, relativas ao componente sintático, as coberturas figurativas que as transformam em atores, locais e marcos temporais, relativas ao componente semântico.

Nesse tocante, Bertrand (2003, p.37) comenta o nível figurativo da leitura em Semiótica:

A significação que se forma e se atualiza na passagem de uma figura a outra, e não em cada uma delas tomada individualmente, pertence precisamente ao que a Semiótica chama de nível figurativo da leitura. Uma impressão de "realidade" se depreende como se tratasse de um quadro pintado (BERTRAND, 2003, p. 37).

Bertrand acrescenta que a passagem de uma frase a outra até o fim do texto só pode ser percebida "como um continuum semântico se postularmos uma isotopia comum que tece uma ligação entre cada figura, pela recorrência de uma categoria significante (...) no decorrer do desenvolvimento discursivo", isto é, se houver "desdobramento das categorias semânticas ao longo do discurso" (BERTRAND, 2003, p.185-187) que caracterize um percurso temático, mais geral e abstrato que figurativo, porque, conforme Bertrand (2003, p.40) "está aberto a um maior número de potencialidades semânticas (...) e já consiste em dar sentido ao sentido".

Diante do exposto no que tange ao modo como a persuasão e a argumentação podem ser tratadas no âmbito da teoria semiótica clássica, passemos a uma discussão acerca de enunciação global no texto sincrético.

\section{A enunciação global no texto sincrético}

Segundo Greimas e Courtés (2008, p.166), enunciação é a "instância que possibilita a passagem entre a competência e a performance (linguísticas), entre as estruturas semióticas virtuais (...) e as estruturas realizadas sob a forma de discurso". Conforme estes autores, a enunciação é, ao mesmo tempo, o lugar de exercício da competência semiótica e a instância da instauração do sujeito (da enunciação). A enunciação enunciada é, assim, apenas um simulacro do dizer do enunciador, isto é, a 
simulação do fazer enunciativo em quaisquer linguagens ou articulação de linguagens.

É, para nós, via enunciação que se dá ocorrência de fazeres persuasivos capazes de gerar efeitos de sentido de objetividade e subjetividade, aproximação e distanciamento, a partir de operações de debreagem e embreagem. Assumindo argumentação como um fazer persuasivo, convocamos Barros (2012, p. 28) para mostrar como as estratégias de persuasão ocorrem no âmbito discursivo.

As estratégias de persuasão do discurso caracterizam o sujeito da enunciação por seu modo de ação. Apresentam-se, sobretudo, como "escolhas" da enunciação de tempo, de espaço e de ator (de pessoa), com a finalidade de convencer 0 destinatário da verdade (ou da falsidade) do discurso enunciado (BARROS, 2012, p. 28).

Essa semioticista, ao aliar a possibilidade de "escolhas" enunciativas a estratégias de persuasão, parece dizer que operações de debreagem ou embreagem, por exemplo, surgem com base em intencionalidades que visam negociações entre enunciador e enunciatário. Por isso é que Fiorin (2007) caracteriza a enunciação como um verdadeiro "jogo de máscaras, de papéis, de imagens, como um teatro, uma encenação", correspondente ao domínio da retórica com sua ideia de persuasão consciente.

Como um ato "consciente", a enunciação é fundadora de texto, que nada mais é do que um enunciado mais amplo, uma totalidade de sentido produto da enunciação. De modo mais claro, textos são caracterizados como conjuntos significantes produzidos por um sujeito da enunciação - que independem da natureza de linguagem, seja verbal, não verbal ou sincrética.

De acordo com a Semiótica, um texto sincrético é aquele que apresenta linguagens em articulação em função de um efeito enunciativo global. A expressão "texto sincrético" foi apresentada por Fiorin (2009), que, com base em Floch - pelas considerações feitas no segundo tomo do Sémiotique. Dictionnaire raisonné de la théorie du langage, publicado em 1986 - e em preceitos de Hjelmslev (1975) acerca de forma e substância, defendeu que, ao invés da expressão semióticas sincréticas, fosse utilizada a denominação textos sincréticos, caracterizada pela apresentação de "uma única enunciação enunciação sincrética, realizada por um mesmo enunciador, que recorre a uma pluralidade de linguagens de manifestação para construir um texto sincrético" (FIORIN, 2009, p.38).

No que tange ao exame de textos sincréticos, Teixeira (2008) expressa consistentemente, com base em Floch, as categorias analíticas da expressão: cromáticas, eidéticas e topológicas. Para as categorias cromáticas, são admitidas as combinações de cores "como procedimento constitutivo de significantes, observável por meio de oposições", como brilhante/opaco, puro/mesclado. Para as categorias eidéticas, que compõem as formas, são verificadas as combinações de linhas, volumes e cores superpostas, como curvilíneo/retilíneo e verticalidade / diagonalidade. Já as categorias topológicas dizem respeito à orientação das formas e do movimento no espaço, a saber, alto/baixo, central/periférico, esquerdo/direito, frente/trás. É importante informar que ainda há outra configuração possível: a matérica, que diz respeito à materialidade do significante (liso/rugoso, leve/pesado, por exemplo) e cuja diversidade pode produzir maneiras particulares de vivenciar a experiência da contemplação (TEIXEIRA, 2009, p.51).

Quando tratamos de texto sincrético, consideramos a sua principal característica apresentação de efeito de enunciação global pela união das linguagens (verbais ou não verbais) envolvidas na construção dos sentidos, ou melhor, pelo ajuste que permite ao leitor tratar as linguagens em articulação como uma linguagem sincrética. Desse modo, essa configuração textual caracteriza-se por uma estratégia enunciativa global, consequentemente a partir de um só enunciador, que "convoca" um enunciatário, conforme o ideal de Greimas e Courtés (2008, p. 171).

No tópico seguinte, apresentamos brevemente os principais regimes de sentido, propostos por Eric Landowski no âmbito da Sociossemiótica: o da programação, o da manipulação e o do ajustamento. Nosso interesse é destacar, sobretudo, o regime de 
ajustamento, tendo em vista que ele requer, no texto sincrético, uma interação de ordem sensível, mais do que inteligível, entre enunciador e enunciatário.

\section{Os regimes de sentido}

A Sociossemiótica, proposta por Eric Landowski, constitui um dos desenvolvimentos da Semiótica greimasiana standard e aborda a questão do sentido no nível das práticas e das interações sociais (LANDOWSKI, 2014). As ideias de Landowski alargaram exponencialmente as condições de aplicabilidade da teoria narrativa, na medida em que sua atenção se volta para as condições de emergência da significação na dinâmica dos discursos e das práticas sociais "reais", vividas.

Para dar conta do sentido, Landowski propõe regimes que traduzem o sentido em interações sociais - programação, manipulação, acidente e ajustamento. A teoria define transições entre esses regimes de sentido, assim como prevê múltiplas superposições e combinações possíveis, apresentando-os como maneiras de estar no mundo ou como "formas" de vida distintas, o que não permite, assim, diferenciá-los com base nos fatores de superioridade ou inferioridade.

Primeiramente, o regime de programação segue o princípio da regularidade, o qual remete à constância das relações entre os efeitos (as ações, os comportamentos) e seus determinantes. Assim, esse regime pauta-se em relações de causalidade previstas, habituais. "É aquele da repetição do mesmo, da «rotina» e do risco mínimo" (LANDOWSKI, 2014, p. 17-20, 31-34). Trata-se de um regime que se caracteriza por uma segurança, uma prudência, pela busca de perfeição, haja vista a não previsão de ocorrência de acidentes tampouco de desvios de qualquer tipo. Como declara Fiorin (2013, p.438), a programação remete a algoritmos de comportamento, por isso é que os sujeitos têm papéis temáticos fixos e estereotipados, o que também justifica a ausência de grandes riscos.

A respeito do regime seguinte - 0 de manipulação - há uma série de graduações que o ligam ao regime da programação, já que ruptura perfectível não há entre eles.

Quando se diz (com razão) que a manipulação corresponde a um fazer querer fazer, pressupõe-se evidentemente que 0 sujeito ao qual o manipulador se dirige não quer de antemão fazer o que se quer que ele faça. Se não, encontrar-se-ia em uma outra configuração: a programação (LANDOWSKI, 2014, p. 92).

Desse modo, consoante Landowski, toda manipulação consiste em fazer outrem desviar-se de sua trajetória para orientá-lo a um projeto de atividade que para ele está "fora do programa". O regime da manipulação é, de modo lógico, fundado na intencionalidade, visto que abrange um ideal estrategista do manipulador. Trata-se de uma operação cujo princípio consiste em empreender procedimentos persuasivos com o objetivo de fazer que o sujeito manipulado "não possa deixar de conformar-se ao querer do estrategista-manipulador" (LANDOWSKI, 2014, p. 48).

Como é visível, a manipulação pauta-se na interdependência dos sujeitos por envolver estratégia e desenvolver em maior proporção a lógica do "fazer fazer", semelhante ao trabalho político, bastante persuasivo, que visa ao acordo de vontades por meio de contratos. O desafio é, assim, o de "prever" a constância comportamental do destinatário. Tudo é questão de cálculo.

Esse cálculo já não é característico do regime de acidente, pois o assentimento é o resultado da comunicação de dois percursos na qual não se pode identificar nem causa (regularidade - programação) e nem finalidade (intencionalidade- manipulação). Tal regime funda-se no princípio da álea (ou melhor, aleatoriedade), do assentimento ao imprevisível, que, sob a figura do «azar», é capaz de fazer fracassar ou vencer qualquer programa em curso, qualquer manipulação, qualquer ajustamento. Queremos dizer com isso que o acidente permite a negação ou a superação dos programas fixados de antemão, ou seja, pode nos colocar, mediante certas descontinuidades, "diante do sem sentido; excluindo toda a possibilidade de antecipação" (LANDOWSKI, 2014, p. 71) e caracterizando-se como uma 
ocorrência do acaso, que não cria valor e não enuncia sentido algum.

No regime do ajustamento, por sua vez, o modo por meio do qual um ator intervém em outro passa por um contato, por um sentir junto e também por um fazer junto, livre de unilateralidade. Vale destacar que ajustamento não denota uma atuação sobre um outro e nem uma subordinação, como ocorre na manipulação, na qual há planejamento para que o outro realize um programa preestabelecido em detalhe. Trata-se de um regime democrático, no qual "os actantes coordenam suas dinâmicas respectivas em função de um princípio de sensibilidade" Landowski (2014, p. 105).

Como um modo de "escapar" dessa monotonia, o regime do ajustamento põe em jogo o processo de contágio, que designa, sob a ótica atual, um caso exemplar do processo de união e que se funda sobre as qualidades sensíveis dos parceiros da interação, isto é, de um lado, a consistência estésica (plástica e rítmica) dos objetos, e, de outro, a competência estésica dos sujeitos" (LANDOWSKI, 2014, p. 39-52), que se difere da competência modal por não se instaurar na lógica da junção. Tal competência estésica obedece ao princípio de sensibilidade, visto que seu exercício supõe, da parte do sujeito, a superação do modo de leitura do mundo baseada no reconhecimento de unidades figurativas pontuais e "uma disposição para capturar efeitos de sentido oriundos das qualidades plásticas próprias aos objetos apreendidos em sua presença imediata" (LANDOWSKI, 2004, p. 96-99).

O contágio, estudado no âmbito do regime de ajustamento, apresenta um princípio fundamental de inerência entre aquele que sente e aquele que é sentido, "de tal forma que não pode mais haver nem determinação causal, nem um 'antes' pressuposto por um 'depois', mas somente coação, concomitância" (LANDOWSKI, 2004, p. 33), o que o coloca na ordem da simultaneidade e 0 define como uma transformação dinâmica e recíproca em ato, ou melhor, ajustamento recíproco. Neste ponto, vale salientar que o contágio não existe antes da experiência semiótica, é por isso que foi conceituado como relação entre sensibilidades.

Landowski apresenta um comparativo acerca dos regimes de sentido:

Os quatro regimes que descrevemos supõem todos, por definição, uma face a face entre, no mínimo, dois atores e, entre eles, o desenvolvimento de processos muito diversos por intermédio dos quais ao menos um dos dois "age" sobre o outro. $\mathrm{Na}$ conversação programada, o que um diz dita ao outro a réplica prescrita pelo uso. No regime do acidente, a irrupção do sentido, ou do sem sentido, é tão perturbadora que o sujeito se encontra estupefato ou extasiado e, em todo caso, desamparado. Sob o regime do ajustamento, cada impulso de um constitui um convite para o outro amoldar-se ao seu movimento. E na manipulação, o fazer persuasivo, se alcança seus fins, transforma o núcleo da competência modal do interlocutor, seu querer, e consequentemente, seu poderfazer. Assim, portanto, trata-se mesmo de regimes de sentido e de "interação" (LANDOWSKI, 2014, p. 95)

Nesse sentido, o fazer persuasivo pelo viés da Sociossemiótica pode ser compreendido pelo modo como esses regimes interagem entre si. Um enunciatário pode, por exemplo, ser convencido, por meio de estratégias, e também mobilizado, por meio de um contágio - pautado no sentido sentido. Assim, conforme os ideais landowskianos, há possibilidade de co-presença entre os regimes: ajustamento manipulador ("contágio" a serviço de um fazer) ou, de lado oposto, a existência de uma manipulação por ajustamento, por exemplo.

O modo da interação (programação, acidente, manipulação, ajustamento) é sempre o resultado de um tipo de relação entre os actantes sustentada por uma determinada dinâmica a partir da qual esta competência relacional de base se estabelece. Esta dinâmica é regida pelos mesmos princípios gerais que definem os regimes, de tal modo que podemos admitir a configuração, por exemplo, de uma programação programada, uma programação acidental, uma programação por manipulação, uma programação por ajustamento e assim sucessivamente. Por esse caminho, admitir uma manipulação por ajustamento é tratar, em outros termos, de um tipo de relação orientada pelo princípio da intencionalidade e pela lógica transacional de um contrato, mas que lança mão, para operar o seu fazer-fazer, de uma dinâmica fusional, ou seja, de um tipo qualquer de contrato ou de uma modalidade de "contágio" (FECHINE, 2013, p. 605). 
O contágio, por caracterizar-se por um fazer sentir, é um fenômeno peculiar da persuasão sensível, sobre a qual falaremos no próximo tópico.

\section{A persuasão sensível na publicidade de cosméticos}

De acordo com os postulados da Sociossemiótica, a persuasão não se baseia apenas em um fazer o outro fazer, mas também em um fazer sentir. É por conta dessa lógica da união do fazer sentir que podemos falar em uma espécie de persuasão sensível que se efetiva entre sensível e inteligível, sobretudo no sincretismo de linguagens, que se caracteriza pela apresentação de linguagens complexas ou, como prefere Beividas (2006), por uma constelação de semioses. Queremos dizer, com isso, que compreendemos o texto sincrético como um locus favorável para o surgimento de estratégias de persuasão fundadas na dimensão sensível do discurso em interação com a dimensão inteligível, logicamente. Essa persuasão sensível pode ser caracterizada como um mecanismo discursivo que articula as dimensões sensível e inteligível do discurso e é regulada no discurso pelos regimes de sentido. Arriscamo-nos a definir essa expressão como um conjunto de estratégias que, de alguma maneira, organizam 0 simulacro da sensorialidade nas interações discursivas.

Para analisar como esse fenômeno se manifesta em textos sincréticos, escolhemos, diante dos limites propostos para este artigo, uma peça publicitária de cosméticos da Revista Natura, referente a uma edição de 2014:

Figura 1 - Revista Natura

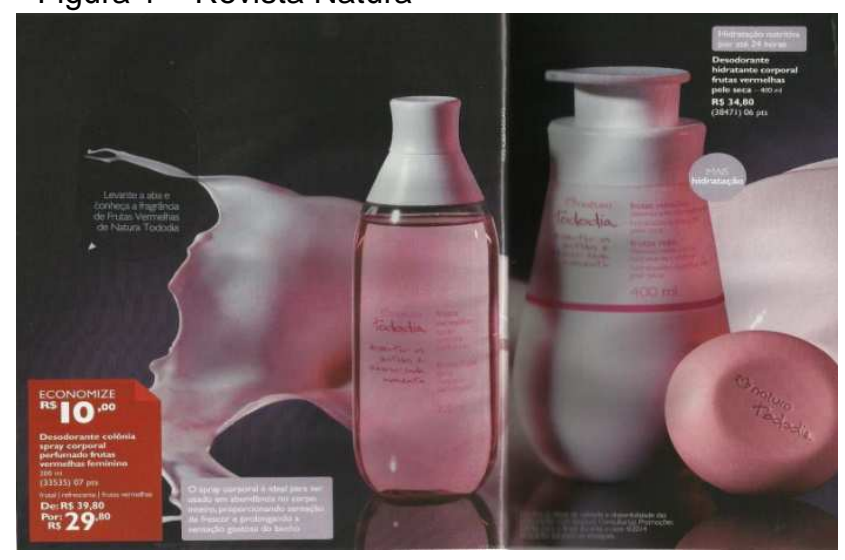

Fonte: Revista Natura - Ciclo 04 de 2014, p. 48-49.

Esse anúncio da Natura se estende por duas páginas e apresenta as imagens de três produtos: de um sabonete e um desodorante-hidratante, do lado direito, e um spray corporal, do lado esquerdo, acompanhadas de textos com informações sobre características e preços de cada um deles.

Se tomarmos como ponto de partida para a análise a dimensão topológica do plano da expressão do anúncio, veremos que a distribuição das figuras dos produtos no lado direito e esquerdo não é ingênua. É consabido que, ao abrir as páginas de uma revista (ou catálogo de produtos) qualquer, 0 leitor tende a focalizar sua atenção, inicialmente, no lado direito da página, para depois explorar o lado esquerdo $^{2}$. Assim, aquilo que deve ser focalizado, bem como a ordem em que deve ser focalizado, fica, em certa medida, condicionado pela forma programada de manusear e ler a própria revista. Em relação ao catálogo da Natura, acontece exatamente isso. A organização espacial das imagens e informações nela contidas insere o enunciatário numa lógica de interação baseada na regularidade pelo hábito de ler esse tipo de revista e encontrar uma previsibilidade na sua diagramação (pela disposição de imagens no centro da página, pelo destaque visual dado aos novos produtos e às promoções, pela apresentação repetida de preços e produtos etc.). Seguindo essa linha de raciocínio, poderíamos pensar que o anúncio em tela estaria privilegiando os produtos apresentados no lado direito, o sabonete e o desodorante-hidratante, de modo que a atenção do enunciatário se voltasse preponderantemente para eles. Entretanto, se observarmos atentamente a diagramação do anúncio, veremos que a disposição das figuras dos produtos escolhidos no lado direito e esquerdo reproduz a ordem lógica, o script ou "roteiro cognitivo" da higiene pessoal, em que primeiro se usa o sabonete (banho), em seguida, o hidratante-

\footnotetext{
2 Essa estratégia de diagramação de jornais e revistas é amplamente estudada e utilizada na área de comunicação, mídia e publicidade, para, dentre outras coisas, medir e gerenciar o nível de atenção de leitores e consumidores sobre notícias, produtos e serviços divulgados na mídia impressa. (cf. HURLBURT, 2002 e SILVA, 1985).
} 
desodorante (cuidado com a pele pós-banho), e, por fim, o spray corporal refrescante (perfumação pósbanho). Diante disso, podemos supor que essa organização espacial de elementos do plano da expressão cria uma isotopia discursiva que reflete um modo de colocação em discurso dos conteúdos escolhidos pelo enunciador para exercer seu fazer persuasivo sobre o enunciatário. Dessa forma, a interação entre enunciador e enunciatário, via texto sincrético, deixa de ser simplesmente uma interação programada, um conjunto de comportamentos previsíveis e estereotipados, e passa a ser vista também como um regime de sentido fundado na manipulação. Nesse regime, a persuasão ocorre não só pelo recurso à previsibilidade e à regularidade, mas também por estratégia. A finalidade agora é convencer o enunciatário da verdade (ou da falsidade) do discurso enunciado para fazê-lo agir, mediante o princípio semiótico de intencionalidade instalado no discurso enunciado, como propõe Landowski. Por conseguinte, a organização diagramática dos elementos do plano da expressão do anúncio consiste não somente em uma sequência de apresentação de produtos e informações, mas em uma estratégia de persuasão do enunciador para fazer que o enunciatário acompanhe o processo de fazer a higiene pessoal em todas as suas fases, incoativa (início), cursiva (meio) e terminativa (fim). Ora, como podemos observar, trata-se de uma aspectualização ${ }^{3}$, que, neste caso, valoriza a duratividade do processo, criando efeitos de sentido de integração e continuidade que, em última instância, podem levar o enunciatário-consumidor a comprar não somente um, mas os três produtos de higiene pessoal. Esses efeitos de sentido são criados, na dimensão plástica do plano da expressão, tanto pela imagem de um líquido que se espraia desde o lado direito até o lado esquerdo da peça publicitária,

\footnotetext{
3 Tradicionalmente, a noção de aspecto vem sendo tratada como uma questão referente ao tempo, cuja marca mais explícita estaria na categoria verbal. Contudo, a semiótica expande essa definição para os três componentes básicos da enunciação, que são o tempo, a pessoa e o espaço. "Podemos caracterizar o tempo através de sua duração, o lugar através de um percurso e o ator através de um processo de transformação, com o posicionamento do observador em qualquer ponto da escala, seja no início, no meio ou no fim" (GOMES, 2011).
}

quanto pela dimensão cromática do anúncio, pois as cores dos produtos não são excludentes, mas sim graduais, compondo um matiz de tonalidades da mesma cor (rosa) que se distribui por todas as imagens dos produtos. No plano da linguagem verbal, o enunciado "prolongando a sensação gostosa do banho" reforça esses efeitos de sentido, pois ilustra bem a valorização da duratividade, ao serem mencionadas somente as fases incoativa ("banho") e cursiva (expressão gerundiva "prolongando"), deixando omissa a fase terminativa do processo.

Ainda na dimensão plástica do plano da expressão, convém mencionar a diferença de enquadramento e mudança de cor na apresentação das informações verbais dos produtos: enquanto as informações qualitativas (características subjetivas dos produtos) são apresentadas sobre um fundo de cor cinza e enquadradas por retângulos (retas) e círculos (curvas), as informações quantitativas (descrição, referências e preços dos produtos) são apresentadas sem enquadramento ou enquadradas em um fundo de cor vermelha. Essa oposição de cores e enquadramentos é significante na medida em que aponta para outra estratégia do enunciador para captar a atenção do enunciatário, ao destacar uma informação pela escolha de uma determinada cor ou tipo de enquadramento e ao criar regularidades plásticas que diferenciam o tipo de informação. Isso ocorre, por exemplo, nos dois textos que acompanham a imagem do spray corporal, no lado esquerdo do anúncio: se, no quadro cinza, o enunciador valoriza a dimensão sensível do discurso pela linguagem verbal, ao reforçar o apelo sensorial, sinestésico do produto ("O spray corporal é ideal para ser usado em abundância no corpo inteiro, proporcionando uma sensação de frescor e prolongando a sensação gostosa do banho"), no quadro vermelho, por sua vez, a cor e o tipo de enquadramento, juntamente à linguagem verbal, ganham destaque, estabelecendo uma tensão entre as dimensões inteligível e sensível do discurso. Dessa maneira, 0 destaque visual dado pela vivacidade da cor vermelha reforça a manipulação pela dimensão sensível do texto, assim como a aba 
dobrada no canto do quadro, que cria uma sinestesia entre os canais sensoriais tátil e visual e transforma o quadro numa espécie de nota (cujo efeito de sentido é poder ser destacável) para chamar a atenção do enunciatário para descontos e promoções; já a manipulação pela dimensão inteligível do discurso, ainda no quadro vermelho, ocorre pela linguagem verbal, devido à forma verbal "Economize", no imperativo, que ganha nuance de subjetividade. Do ponto de vista semiótico, o verbo no imperativo consiste em uma debreagem enunciativa, que instaura a presença da enunciação no enunciado, criando o efeito de apelo e de interlocução com o enunciatário, ao mesmo tempo em que estabelece uma tentativa de manipulação por tentação (se você comprar, economiza dinheiro).

As estratégias de persuasão, de caráter mais sensível, convocam para o texto sincrético mais um regime de sentido, o ajustamento. A interação por ajustamento, como já vimos, requer estratégia diferenciadas de persuasão/argumentação, fundadas, em última instância, numa lógica de "união" entre sujeitos ou entre sujeitos e objetos, cujo foco não é mais somente fazer o outro (dever, querer, poder) fazer, mas, sobretudo, fazer o outro sentir. Ou seja, trata-se de uma persuasão sensível, que coloca em cena, de um lado, uma competência estésica por parte dos participantes para sentir e, do outro, uma consistência estésica dos objetos, que possibilita uma comunicação não mais cognitiva, mas, sim, de ordem afetiva e sensorial.

$\mathrm{Na}$ peça publicitária em questão, a presença de uma aba transparente e destacável, localizada na parte superior esquerda do anúncio, contendo o enunciado "Levante a aba e conheça a fragrância de frutas vermelhas de Natura Todo Dia", pode ser considerada uma estratégia de persuasão sensível que coloca o enunciatário sob o regime de ajustamento. Analisemo-la.

O texto verbal da aba começa com os verbos imperativos "levante" e "conheça". Ambos, por estarem debreados enunciativamente, criam o efeito de sentido de interlocução, de aproximação, entre enunciador e enunciatário. Vale observar, contudo, que enquanto a forma verbal "levante" solicita uma ação pragmática do enunciatário, um fazer (levantar a aba), a forma verbal "conheça" requer outro tipo de resposta, de natureza cognitiva, da ordem do saber. Vale notar que, na própria sintaxe, a conjunção "e", excede seu valor de adição e adquire valor consecutivo (de efeito ou de resultado). Ou seja, não se trata apenas de um comando ou de um pedido, mas de uma estratégia argumentativa que lança o enunciatário numa manipulação por sedução, cuja modalidade de base é o querer (querer cheirar). Em decorrência disso, a força persuasiva da sequência de verbos, repousa, em termos modais, em um "saber fazer querer" do enunciador e um possível "querer saber fazer" por parte do enunciatário. Outro aspecto que merece destaque é o papel argumentativo do complemento do verbo conhecer ("fragrância de frutas vermelhas") e do sintagma preposicionado que o segue ("da Natura Todo Dia"). Supomos que o verbo logicamente previsível, esperado no enunciado, seria o verbo sentir ou cheirar e não o verbo conhecer, já que para conhecer uma fragrância é preciso cheirá-la, senti-la primeiro. Ora, a escolha do verbo conhecer não é fortuita, pois indica que o cheiro da fragrância já não é mais pura percepção olfativa, pois o aroma está organizado de acordo com o universo de valores do sintagma preposicionado "Natura Todo Dia" (não se trata de um aroma de frutas vermelhas qualquer, mas o da Natura). Por isso, ao levantar a aba para sentir o cheiro da fragrância, a presença do verbo conhecer já organiza semioticamente, pela ordem do saber, a sensorialidade olfativa, a percepção do enunciatário. Ainda temos o sintagma nominal preposicionado "fragrância de frutas vermelhas", que cria um simulacro sinestésico composto por três ordens sensoriais, o olfato (fragrância), o paladar (frutas) e a visão (vermelhas), cuja mistura intensifica a manipulação pela dimensão sensível do discurso. Como se vê, trata-se de uma estratégia de persuasão que opera com os conteúdos sensíveis das duas linguagens, a verbal e a não verbal.

A persuasão sensível, entretanto, não para por aí. O comando para levantar a aba e conhecer o 
aroma de frutas vermelhas exige do enunciatário a interação sensorial com a matéria física do texto, isto é, é preciso tocar e cheirar a página, que nada mais é do que um simulacro da fragrância do produto. Vê-se que a estratégia de persuasão não se resume a um fazer o outro fazer, pois se trata, agora, de uma comunicação por "contágio", cujo objetivo é também fazer o outro "ajustar-se" para sentir.

\section{Conclusão}

Para conquistar a confiança e a adesão do enunciatário, as estratégias de persuasão no texto sincrético, como vimos, extrapolam os limites da linguagem verbal para compreender também a linguagem não verbal. A articulação de diferentes linguagens cria uma enunciação sincrética global, que envolve tanto a dimensão inteligível quanto a dimensão sensível do discurso. É por essa razão que podemos falar em persuasão sensível.

Do ponto de vista sociossemiótico, a persuasão sensível seria o resultado de um conjunto de estratégias discursivas que pressupõe diferentes regimes de sentido (a programação, a manipulação e o ajustamento) entre enunciador e enunciatário. Por conta da interação desses regimes, o fazer persuasivo do enunciador se constrói não somente pela lógica do fazer o enunciatário fazer, mas também pela lógica de fazê-lo sentir. É possível, então, falarmos da presença de uma verdadeira "retórica polissensorial" no texto sincrético aqui analisado. Esse termo, cunhado por Fontanille (2005), é usado para designar a forma de gerenciar as heterogeneidades sensoriais, regrar tensões e resolvê-las em figuras significantes.

Sendo assim, a noção de argumentação, de um ponto de vista semiótico, deixa de ser concebida apenas como a tentativa de modificar ou reforçar, pelos recursos da linguagem, a visão de mundo do enunciatário e passa a ser concebida como tentativa de fazer o outro aderir não somente a uma tese, mas também a modos de pensar e de sentir. Isso permite à argumentação, tomada como sinônimo de arte de persuadir, "tratar do vasto leque de discursos, tanto os privados, quanto os públicos, que circulam no espaço contemporâneo, e reivindicar seu lugar nas Ciências da Linguagem", como bem assinala AMOSSY (2011, p. 130).

\section{Referências}

AMOSSY, Ruth. L'argumentation dans le discours. Troisième édition. Paris: Armand Colin, 2000.

Argumentação e Análise do Discurso: perspectivas teóricas e recortes disciplinares. Tradução de Eduardo Lopes Piris e Moisés Olímpio-Ferreira. Revista Eletrônica de Estudos Integrados em Discurso e Argumentação, Ilhéus, n. 1, p. 129-144, nov.2011.

BARROS, Diana Pessoa Luz. Teoria do discurso: fundamentos semióticos. 1. Ed. São Paulo: Atual, 1988 [2001]

Paulo: Ática, 4. ed, 2005.

Teoria semiótica do texto. São

Algumas reflexões semióticas sobre enunciação. In: DI FANTI, Maria da Glória; BARBISAN, Leci Borges (orgs). Enunciação e discurso: tramas de sentidos. São Paulo: Contexto, 2012, p.28-43.

BERTRAND, Denis. Caminhos da semiótica literária. Bauru: EDUSC, 2003, p.37-344.

DUCROT, Oswald. Polifonía y argumentación. Tradução de Ana Beatriz Campo e Emma Rodríguez. Cali: Universidad del Valle, 1988.

FECHINE, Yvana. Ainda faz sentido assistir à programação de TV? Uma discussão sobre os regimes de fruição na televisão. In: OLIVEIRA, Ana Cláudia de (org.). As interações sensíveis. Ensaios de Sociossemiótica a partir da obra de Eric Landowski. São Paulo: CPS e Estação das Letras e das Cores, 2013, p.589- 614.

$\mathrm{FLOCH}$, Jean - Marie. Les formes de l'mpreinte: Brandt, Cartier-Bresson, Doisneau, Stieglitz, Strand. Périgueux, Pierre Fanlac, 1986, p.218-233

FIORIN, José Luiz. O sujeito na semiótica narrativa e discursiva. Todas as Letras: São Paulo, v. 9, n. 1, p. 24-31, 2007.

Para uma definição das linguagens sincréticas. In: OLIVEIRA, Ana Cláudia de; TEIXEIRA, Lúcia. (Org.). Linguagens na comunicação: desenvolvimentos de semiótica sincrética. São Paulo: Estação das Letras e Cores, 2009, p.33-38.

Estruturas narrativas. In: OLIVEIRA, Ana Claudia de (Ed.). As interações 
sensíveis. Ensaios de sociossemiótica a partir da obra de Eric Landowski. São Paulo: CPS e Estação das Letras e das Cores, 2013, p. 435452.

Contexto, 2015.

$$
\text { Argumentação. São Paulo: }
$$

FONTANILLE, Jacques. Significação e visualidade: exercícios práticos. Porto Alegre: Sulina, 2005, p.37-105.

GOMES, Regina Sousa. Aspectualização em poemas publicados em sites de poesia. Paris, 2011. [texto inédito].

GREIMAS, Algirdas Julien et Joseph COURTÉS. Sémiotique. Dictionnaire raisonné de la théorie du langage, tome 2, Paris, Hachette, 1986.

Dicionário de Semiótica. 7. ed. São Paulo: Contexto, 2008, p.99- 532.

HJELMSLEV, Louis. Prolegômenos a uma teoria da linguagem. São Paulo: Perspectiva, 1975.

HOUAISS, Antônio. Dicionário eletrônico Houaiss da Língua Portuguesa. Rio de Janeiro: Objetiva. Versão 1.0. 1 [CD-ROM], 2001.

HULBURT, Allen. Layout: o design da página. São Paulo: Nobel, 2002.
LANDOWSKI, Eric. Modos de presença do visível. In: OLIVEIRA, A. C. de (Org.). Semiótica plástica. São Paulo: Hacker editores, 2004, p.101.

Interações arriscadas. Trad. Luiza

Helena Oliveira da Silva. - São Paulo: Estação das Letras e Cores: Centro de Pesquisas Sociossemióticas, [2005] 2014.

LOPES, Ivan Carlos; BEIVIDAS,Waldir. Veridicção, persuasão, argumentação: notas numa perspectiva semiótica. v. 9, n. 1. São Paulo: Todas as Letras, 2007.

PERELMAN, Chaim; OLBRECHTS-TYTECA. Tratado da argumentação: a nova retórica. São Paulo: Martins Fontes,1999.

SILVA, Rafael Sousa. Diagramação: o planejamento visual gráfico na comunicação impressa. São Paulo: Summus, 1985.

TEIXEIRA, Lúcia. Razão e afeto: a argumentação na crítica de arte. Alfa, São Paulo, v.50, n.1, p.145158, 2006

Leitura de textos visuais: princípios metodológicos. In: BASTOS, Neusa Barbosa (Org.). Língua Portuguesa: Lusofonia - memória e diversidade cultural. São Paulo: EDUC, 2008, p. 299-306.

\section{COMO CITAR ESSE ARTIGO}

TORRES, Lyssandra Maria Costa; LEITE, Ricardo Lopes. A PERSUASÃO SENSÍVEL NO TEXTO SINCRÉTICO: UMA LEITURA SOCIOSSEMIÓTICA. Signo, Santa Cruz do Sul, v. 42, n. 73, jan. 2017. ISSN 1982-2014. Disponível em: <https://online.unisc.br/seer/index.php/signo/article/view/7994>. Acesso em: . doi: http://dx.doi.org/10.17058/signo.v42i73.7994. 